\title{
Asynchronous Online Course Designs: Articulating Theory, Best Practices, and Techniques for Everyday Doctoral Education
}

\author{
Michael M. Grant (i) \\ Department of Educational Studies, University of South Carolina \\ michaelmgrant@sc.edu
}

\begin{abstract}
Early online course materials were text-based and relied heavily on discussion forums as the de facto tool for interactions. Faculty members today, however, have many other choices for course design and course materials. There is not consensus for online course design guidelines or principles, though. Choices in course design by faculty members directly impact the quality of instruction and student learning experience. This article shares some of our theoretical and practical decisions faculty members at the University of South Carolina employ for online course design. Our experiences and decision-making may be useful for other members of the Online Ed.D. CPED Improvement Group (Online Ed.D. CIG), as well as other programs who may be experiencing emergency remote teaching as a result of the COVID-19 pandemic, making an evolutionary transition to online or blended education, or considering a future transition to a fully online program. Links to the strategies and tools mentioned throughout this essay are collated in a list at the end.
\end{abstract}

KEYWORDS

online course design, asynchronous courses, doctoral education, instructional design, teaching online

Early online course materials were predominantly text-based and relied heavily on discussion forums as the de facto tool for interactions (Anderson, 2003; Garrison et al., 2000). Faculty members today, however, have many other choices for course design and course materials. Faculty members primarily use institutional course management systems (CMS), such as Instructure Canvas and Blackboard Learn (Baldwin \& Ching, 2019; Edutechnica, 2020), to structure courses, deliver learning contents, facilitate learning activities, communicate with students, and assess and evaluate student learning. Across these many course decisions, faculty members also select a variety of pedagogies, generate novel instructional content, curate existing digital resources, require students to use web-based tools, create and repurpose assessments and rubrics, and communicate with students through course announcements, discussion forums, social media, audio/video recording and conferencing systems, and feedback (Martin, Budhrani, et al., 2019; Martin, Ritzhaupt, et al., 2019). The decisionmaking for online course design and course materials is complex.

There is not consensus for online course design guidelines or principles, though (Martin, Budhrani, et al., 2019). Choices in course design by faculty members directly impact the quality of instruction and student learning experience. Well-designed online courses can increase student satisfaction of the courses (Alizadeh et al., 2019; Alqurashi, 2019; Sadaf et al., 2019). Therefore, to address issues of online course quality, colleges and universities have implemented a number of strategies to improve course design. For example, institutions use or require a course design template because it provides students a common, or standardized, navigation experience (Collins et al., 2014; McGhan et al., 2015). Other institutions

New articles in this journal are licensed under a Creative Commons Attribution 4.0 United States License. mandate online courses pass reviews for quality standards (see e.g., Baldwin et al., 2018; Gilliham \& Williams, 2020; McGee \& Reis, 2012).

Still, there are few published descriptions of effective online course designs with enough rich detail for other online faculty members to repurpose or translate into their own courses (cf. Strecker et al., 2019). The Carnegie Project on the Education Doctorate (CPED) member institutions, however, hold both the responsibility and opportunities to foster and share resources, curriculum, and tools to support Ed.D. redesign. To that end, this article is a contribution to support effective online course design and course materials development.

\section{BACKGROUND}

The Learning Design and Technologies concentration (originally Educational Technology) of the Educational Doctorate at the University of South Carolina began in Fall 2016. Our program began fully online and asynchronously. As of Fall 2020 , our program faculty had admitted 13 cohorts of students with approximately 150 students enrolled at any one time. We have previously described the structures of our program, strategies we have used to develop novice researchers and academic writers, and how our program is evolving (Arslan-Ari et al., 2018, 2020).

Currently, our curriculum contains different types of asynchronous courses. We have technical skills courses that focus on students developing foundational knowledge and skills of instructional design and technology competence with current 
technology tools. These courses include instructional design and assessment, instructional media development, online course design and development, and developing learning and instruction for diverse learners (e.g., accessibility). These courses are specific to our Ed.D. concentration, and they combine theory, research, and principles with significant technology tools applications. These courses typically have a significant number of applied projects, and they often build to a culminating instructional product. Other courses are typical of those in education doctoral programs, such as learning theory and instructional models, applied research methods, evaluation and synthesis of research, and dissertation preparation courses.

Online teaching and learning are an essential branch of our field. We have extensive professional knowledge and skills in this area. Therefore, while our field is aware of conventions, best practices, and research to support effective online teaching and learning, many CPED programs' faculty members may not attend consistently to professional practice, publications, and professional development that address distance education. As such, I felt this special issue of Impacting Education themed to online Ed.D. programs may be an apt outlet to elucidate some of our purposeful theoretical and practical decisions for online course design. Our experiences and decision-making may be useful for other members of the Online Ed.D. CPED Improvement Group (Online Ed.D. CIG), as well as other programs who may be experiencing emergency remote teaching (Hodges et al., 2020) as a result of the COVID-19 pandemic, making an evolutionary transition to online or blended education, or considering a future transition to a fully online program. Links to the strategies and tools mentioned throughout this essay are collated in Appendix $A$ at the end.

\section{Acknowledgements and Subjectivities}

I have been teaching online or through blended methods for approximately 18 years. As a result of this extended experience, many of the course design strategies we currently use in our education doctorate program were developed previously in collaboration with past colleagues at the University of Memphis, namely Lee Allen, Trey Martindale, and Clif Mims, and with current colleagues at the University of South Carolina, including Fatih Ari, Ismahan Arslan-Ari, and Erin Besser. In addition, I was trained as a secondary education career and technical education teacher for graphic communications at Clemson University, subsequently teaching there as a graduate teaching assistant and an instructor. So, much of my pedagogy and syllabus design were informed by mentors and colleagues there, particularly Nancy Leininger, Page Crouch, Sam Ingram, and John Leininger. Moreover, it would be disingenuous for me to fail to acknowledge critical friends, specifically John Curry (Idaho State University) and Charles B. Hodges (Georgia State University), who have informed and improved my course designs through peer reviews, informal discussions, and sharing sessions at professional conferences.

Reflexively, my own lines of research focus on inquiry methods, such as project-based and problem-based learning, and instructional message design, so these are inherent within my course designs. Cognitivist (Ertmer \& Newby, 1993) and constructionist (Papert, 1991) pedagogies have informed my instructional designs, and these are discussed in depth further below. As such, I state these subjectivities to concede to readers that while the strategies, techniques, and pedagogies presented are theoretically-sound and practically tested, the resulting designs and materials are not the only best practices in which online course designs can be implemented successfully. Indeed, other designs may be equally effective with differing pedagogical beliefs (Ertmer \& OttenbreitLeftwich, 2010) and constraints. For example, across all of the universities I have worked, none have been subject to union contracts, which may impact academic freedoms, instructional designs, and faculty evaluations (e.g., McGhan et al., 2015). So, the extent to which these course design methods can be applied, that is with any practical or internal generalizability, in other contexts is situated with the reader.

\section{PLANNING AN ONLINE COURSE DESIGN}

Course design is student, context, and content dependent. Initially, our faculty analyze our students' goals, their background knowledge and skills, and their preferences for adult learning (e.g., collaboration, choice, rationales for learning) (Knowles, 1975; Morrison et al., 2013). In addition to considering our students, we also consider contexts - both the learning context, where and how online learning will occur, and the students' work contexts. What we can discern from our students about how they learn online informs what we know about how adult students learn online in general. For example, students reported to us that consistent writing groups across multiple courses was valued, and the students preferred to choose their communications mediums. Students also reported they tended to work in concentrated segments of time, which were often at night or on weekends and typical of other adult online students (Glazier, 2016). Moreover, we consider the applicability and adaptability of new knowledge and skills within constraints students may have in their work contexts to apply any new skills or affect change. Finally, we consider the content, identifying terminal objectives or performances and aligning instructional content, activities, and assessments. These front-end analysis considerations impact our course designs for function and form. However, there is no commonly agreed upon list of course design components or characteristics. One of the most common findings, though, from literature is effective online faculty members clearly organize and structure learning contents (Crews \& Butterfield, 2014; DiPietro et al., 2008; Martin, Ritzhaupt, et al., 2019).

\section{Structuring and Organizing an Online Course}

Effective online instructors report using a systematic approach to their course content designs (Martin, Ritzhaupt, et al., 2019), and they focus on alignment among course learning goals, activities, and assessments, which is commonly referred to as backwards design (Wiggins \& McTighe, 2005). Kearns and Mancilla (2017) reported the most common finding from online course instructors participating in their faculty development was an awareness of and "attention to alignment of course components" (p. 194). So, a course's structure and organization should communicate and facilitate the learning contents. More granularly, online faculty members generally structure their courses with units, modules, or weeks (Bates, 2019; Bonfiglio et al., 2016; Martin, Ritzhaupt, et al., 2019). For example, McGee and Reis (2012) presented a typical course planning table that allows structuring course content and ensuring alignment as described above. See Figure 1 for a template I have used to design my own courses and have used in professional development with faculty members. A similar template is available from the City University of New York and the Course Mapping Guide. 


\begin{tabular}{|c|c|c|c|c|c|}
\hline \multicolumn{6}{|c|}{ Planning an Online Course } \\
\hline Unit/Week & Topics & Objectives & Readings/Media & $\begin{array}{c}\text { Interaction with } \\
\text { Content }\end{array}$ & Assessment \\
\hline $\begin{array}{l}\text { Organize by } \\
\text { units or } \\
\text { weeks }\end{array}$ & $\begin{array}{l}\text { List the topic for } \\
\text { the unit or week }\end{array}$ & $\begin{array}{l}\text { List the objectives } \\
\text { (identify Bloom's } \\
\text { level for each) }\end{array}$ & $\begin{array}{l}\text { List the readings and media to be } \\
\text { consumed and digested. Consider } \\
\text { media from graphic organizers, screen } \\
\text { sharing videos, YouTube, Slideshare, } \\
\text { etc. }\end{array}$ & 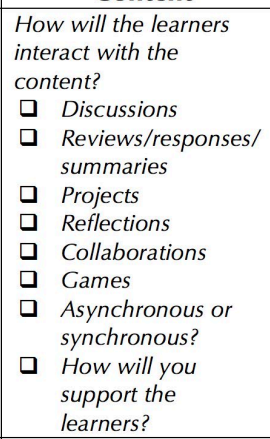 & $\begin{array}{l}\text { How will the objectives be } \\
\text { assessed? } \\
\square \text { Objective test items } \\
\square \quad \text { Performance-based } \\
\text { (consider multiple } \\
\text { representations of } \\
\text { knowledge) } \\
\square \quad \text { Both? }\end{array}$ \\
\hline
\end{tabular}

Figure 1. Course design planning document to align objectives, readings/media, interactions, and assessments (Adapted from University of Maryland-College Park)

Our courses are organized around weeks, modules, or units based on the course content, course sequencing, or instructor's preferences for clarity. While our university has not mandated a specific course template (although they do provide one), we use a consistent structure and in-house template described in detail below. This strategy reduces cognitive load for students and supports usability. A specific theme (i.e., colors, fonts, graphics) may change depending on the course, though, (see Figures 2 and 3 for two examples). An introductory unit in our online courses contains separate pages for a welcome message, the course syllabus, instructor's contact information, course expectations, a getting started assignment focused on preparations as an online learner for the doctoral student and the student's computer, and a getting acquainted assignment to quickly engage our students.

The structure of each unit is consistent across all of our courses. An overview page presents the structure of the unit to the student. Figures 2 and 3 depict overview pages from two different courses. The overview contains the following sections and components:

- A short introduction of the unit or topic is presented. Text and embedded media (e.g., slideshows, videos, graphics, graphic organizers) are purposefully used to arouse student's attention or stimulate recall.

- Standards and/or objectives are listed. Professional association standards are listed here for alignment and for accreditation reviews. Terminal objectives are listed for students to acknowledge expectations.

- Required readings and media are noted, including any texts and other media learners should engage with.

- An additional learning resources section is included for optional texts, supplementary resources, collections of curated bookmarks to tools or instruments, and links to relevant sites or examples.

- An activities or assignments section briefly lists the activities students will engage in to apply and process the new knowledge and skills from the required readings and media. These activities may include projects, discussions, or assessments.
So, while the structure is consistent for students, the design and content are adjusted based on the learners' needs and curriculum goals.

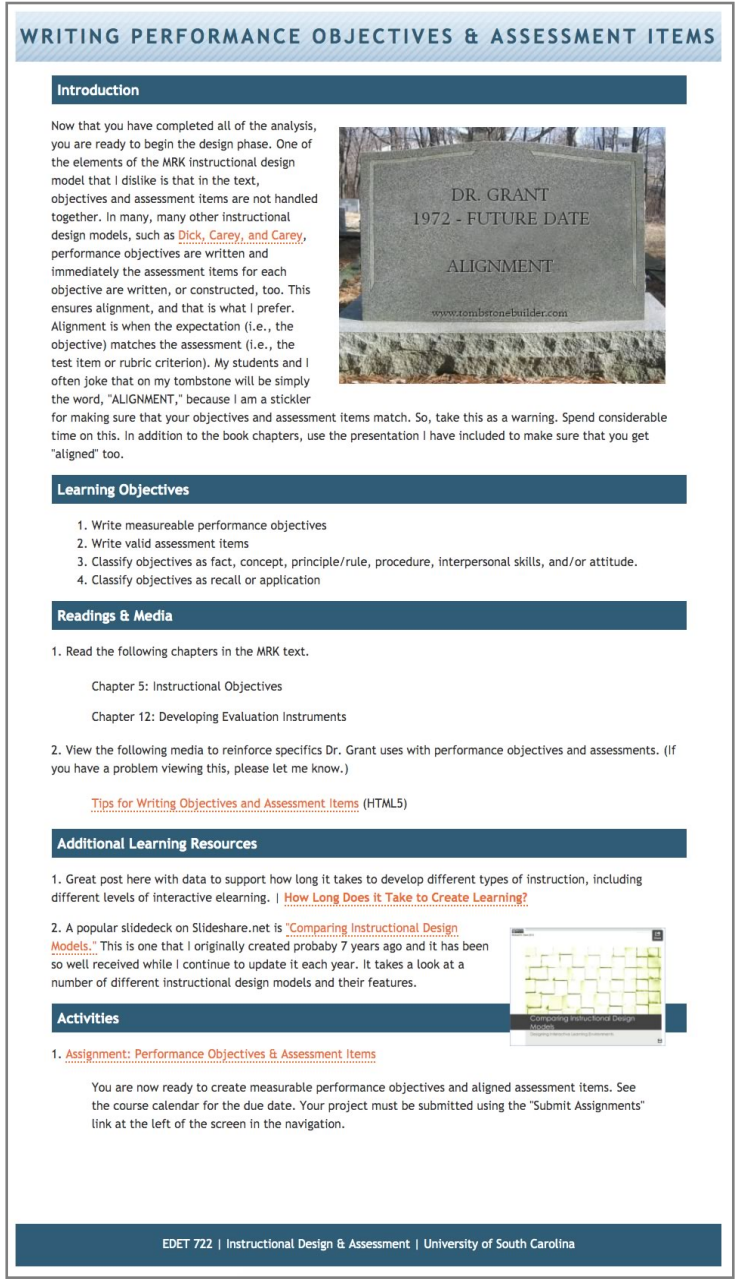

Figure 2. Example of a module/unit overview pages in an introductory instructional design course. A common course template and structure is used across all units and courses. 


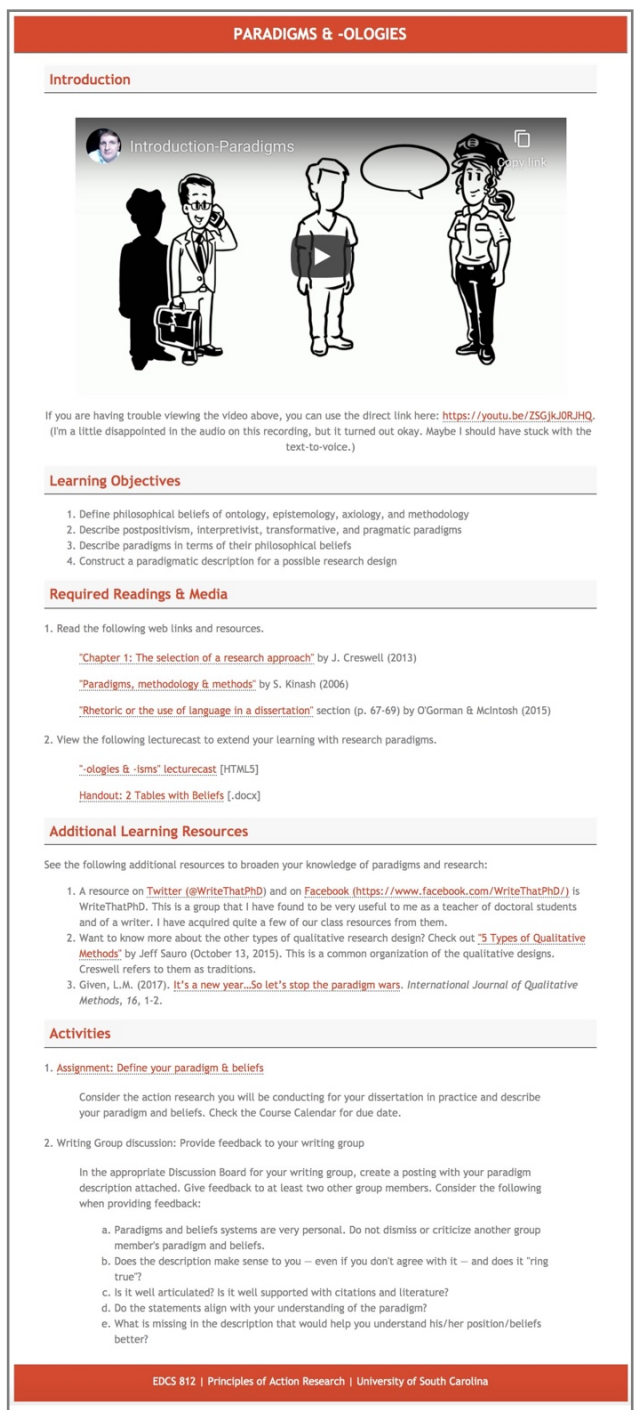

Figure 3. Example of a module/unit overview pages in an introductory action research course. A common course template and structure is used across all units and courses.

\section{INTEGRATING THEORY, PEDAGOGY, AND DESIGN}

Our field is founded in instructional design, and as such, it is firmly rooted in the practice of design (Smith \& Boling, 2009). Therefore, many of our course assignments employ design or designerly thinking. Johansson-sköldberg and Woodilla (2013) categorized the practices of design and designerly thinking as five processes or activities: (a) the creation of artifacts, (b) reflexive practice, (c) problem-solving, (d) reasoning or making sense of designer actions, and (e) creation of meaning. Instructional design problems are complex and ill-structured, and many design decisions are based on constraints that become evident as the problem evolves.

Course assignments, specifically for our technical courses, are guided by constructionist learning theory (Kafai \& Resnick, 1996; Papert, 1991), where students learn best when building or making.
As an extension of constructionism, project-based learning (Grant, 2018; Krajcik \& Blumenfeld, 2006) frames the process for the production of a public, shareable learning artifact that represents student learning. Using theories of design and constructionism with a model of project-based learning, we create activity and assignment web pages. Web pages translate both the structure of project-based learning but also professional standards for message design and web page development. Each of these are described further.

\section{Translating the Theory and Pedagogy}

Activities and assignments outline a product and the process for accomplishing the project, where the project - both process and product - align with the learning goals for the unit (e.g., SaundersStewart et al., 2012). Like the unit overview pages, activity and assignment web pages also employ a consistent structure across a course and across our program. The activity and assignment web pages typically include the following sections and components:

- A brief one- to two-sentence description of the assignment.

- A list of requirements, components, or steps in the assignment.

- Curated resources, such as articles or media to support the assignment or exemplars, templates, or models to scaffold performance.

- Clear directions for submitting the assignment.

- A grading rubric, which may vary in its complexity depending on the assignment.

Contingent on the complexity of the assignment or based on previous feedback, two other sections may be included on the assignment page:

- A suggested strategy to provide conceptual and strategic scaffolds (Hill \& Hannafin, 2001) for students to work through the assignment.

- A screen recording of the faculty member talking through the assignment purpose and requirements, indicating common errors or misunderstandings.

For example, in an introductory instructional design course, students follow a well-established model to design and develop computer-based instruction (i.e., Morrison et al., 2013). One assignment in this course requires students to generate performance objectives and accompanying assessment items. This assignment as seen in Figure 4 follows the assignment description provided earlier:

- A brief statement of the assignment and its connection to prior work;

- A list of requirements for performance objectives, classifications, and objective test items;

- A suggested strategy to scaffold their performance;

- A template for organizing students' work;

- Exemplars from prior students to depict variation in topics and work contexts;

- Explicit instructions for submitting the assignment inside our CMS; and

- An assessment rubric that is replicated inside of our CMS assignment grading function. 


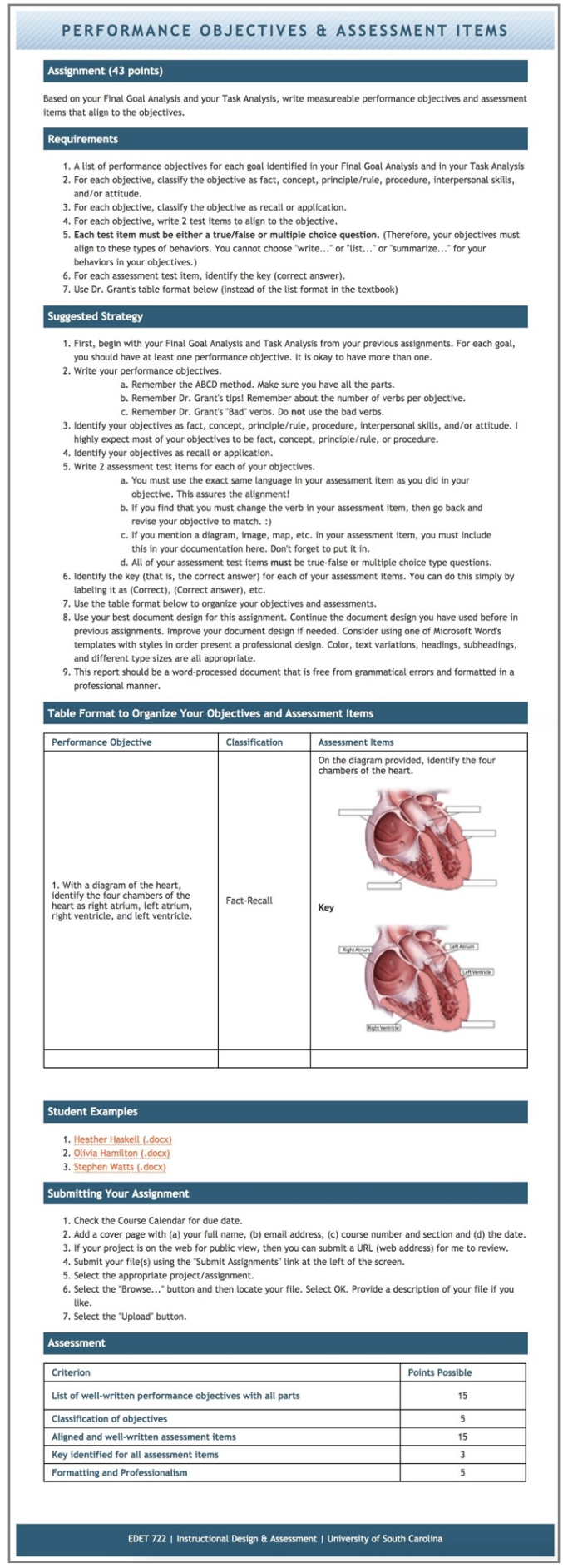

Figure 4. Example of an assignment page with common sections across courses. This example is from an introductory instructional design course.

\section{Message Design and Web Page Development}

Instructional message design employs principles of visual design and strategies for cognitive information processing together to support learning. Applied strategies for cognitive information processing are also used to support learning. Such strategies include (a) signaling in text through using text structures, section headers, text transformations, and signaling words (Morrison et al., 2013); and (b) selection of graphics and multimedia based on their functions (Clark \& Lyons, 2011). The instructional message design often culminates in a template, like the one we use and seen in Figure 4.

Technically, we generate the templates for our course materials as web pages. We use professional web design software, such as Adobe Dreamweaver, and we adjust the underlying HTML code and cascading style sheets (CSS) as needed for the template design. Many of our stylesheets were collected years ago from free or open source repositories, and their simplicity has served us well over many years, courses, and different institutions' CMSs.

We build our course materials as web pages for three reasons. First, message design and web page development are topics and skills relevant to our curriculum. So, we purposefully model these for our students, so they can see their utility and versatility. Second, by designing a significant portion of our course materials outside of our institution's CMS, we have made our course materials durable and interoperable (Day \& Erturk, 2017; Gonzalez-Barbone \& Anido-Rifon, 2008). Durability means that the learning materials can withstand changes and updates in systems, such as changes in institutional CMSs or when faculty members change institutions. Interoperability means the learning materials can be used across a number of different types of systems. For example, our course materials web pages work within our institution's CMS but they would also function as a stand-alone web site on the internet or as a ZIP package sent to a student or colleague. Finally, because we have used HTML to build the structure and contents of a web page and the CSS separately to style the web page, we can change the CSS style to alter all pages across an entire course. These are significant advantages over learning contents built wholly inside of an institutional CMS. However, institutional requirements for online courses and intellectual property may limit some of these advantages (Day \& Erturk, 2017; Zawacki-Richter, 2017)

It would also be misleading, however, if I did not acknowledge the limitations of the methods we use for creating content. Building course materials this way does not account for many functions CMSs do afford faculty members and students, such as textbook integrations, assessment strategies, or embedding tools, such as discussions, directly into the course contents at the point of need (Dron \& Anderson, 2014).

\section{DEVELOPING LEARNING MATERIALS}

The development of our various individual course learning materials is informed by Mayer's cognitive theory of multimedia. Mayer's (2008) theory is grounded in information processing and the limitations of working memory (Emory, 2019; Kirschner et al., 2006), dual coding theory for processing visual and verbal information (Paivio, 1991; Reed, 2006), cognitive load theory (Sweller et al., 1998), and instructional message design principles (Fleming \& Levie, 1993; Ramlatchan, 2019). Multimedia, Mayer asserts, can be more effective for learning because it can be encoded through dual channels and actively processed from working memory to long-term schemata. These principles and theories are embedded within our curriculum and we are obligated to model them for our students. 


\section{Developing Rich Media}

Throughout an online course, students repeatedly interact with learning materials in learning interactions. While there are three types of interactions - that is, (a) student-content, (b) studentinstructor, and (c) student-student (Anderson, 2003) - this section on developing multimedia is most aligned with student-content interactions, which occur with various media. Students-content interactions can occur with various media, including text, hypertext, graphics, audio, video, and other dynamic media such as virtual reality, augmented reality, mixed reality, simulations, and microworlds (Clark \& Lyons, 2011; Tuovinen, 2000). So different media function in distinctive ways and afford distinct student-content interactions.

Where possible, we embed rich media into our course materials. Rich media blend "text, audio, video, and dynamic motion .... [to increase] student interaction and engagement" (Havice et al., 2010 , p. 54). These media can include screen recordings for technical instructional development skills or how-to tutorial videos. Videos and slideshows may be embedded from popular sites, such as YouTube and Slideshare. Audio narrations and podcasts can also be hyperlinked or embedded. Because recorded lectures are so common in online course materials, I have included a subsection that addresses these media directly.

\section{Recording Lectures}

There are a number of current technologies that afford online faculty the ability to create recorded lectures, including screen recording software such as Screencast-o-matic and Screencastify; video recording inside of web conferencing software such as Blackboard Collaborate Ultra and Zoom; and audio narration in digital presentation software such as Microsoft PowerPoint and Apple Keynote.

One strategy that has worked well for recorded lectures has been to use iSpring Suite. The full-featured iSpring Suite is a plugin to Windows-only Microsoft PowerPoint with much functionality to create interactive elearning courses. Specifically for recorded lectures, though, I have found the primary functionality of publishing narrated slideshows to HTML5 web pages to be successful for our students. Also, in planning for future reuse, individual slides can be changed/updated and narration re-recorded, and the file is quickly ready to publish again. See Figures 5 and 6 for an example of using iSpring and publishing to HTML5 from iSpring.
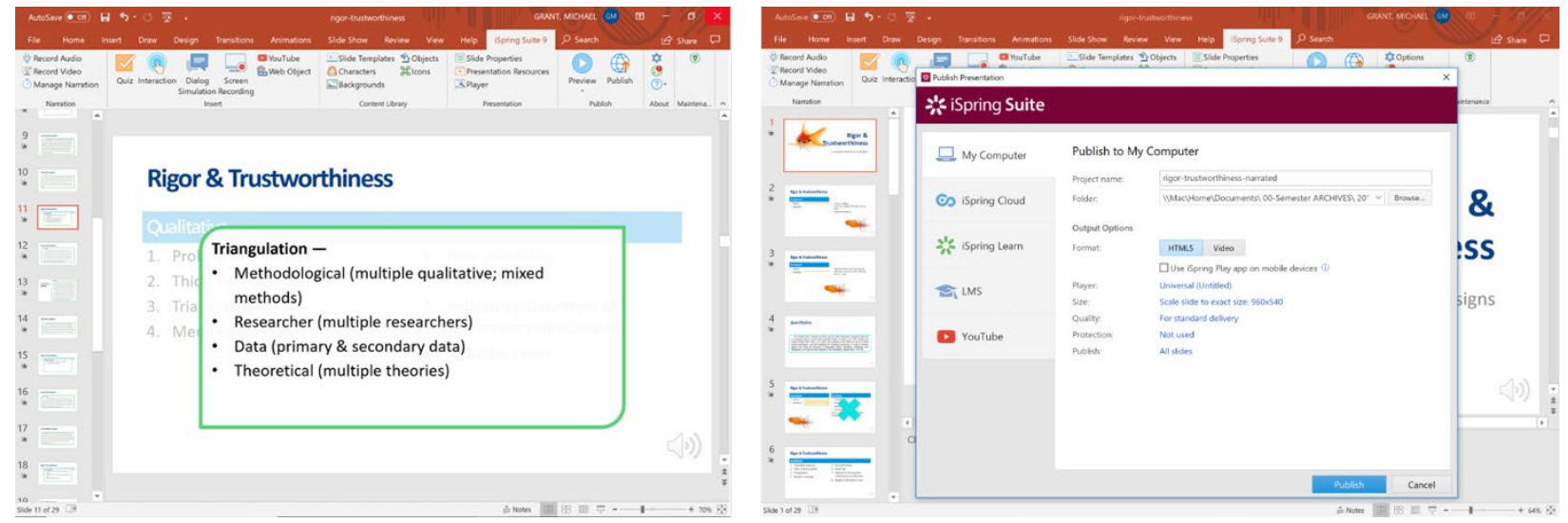

Figure 5. Example of audio narrated slides with iSpring Suite tab in the Microsoft PowerPoint ribbon (left) and publishing the slides to HTML5 web pages (right).

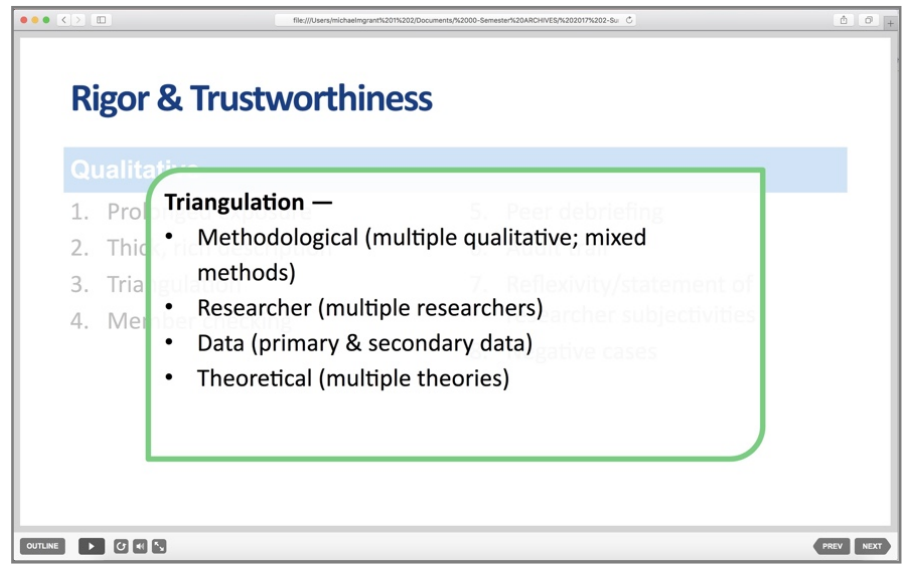

Figure 6. Playing narrated slides in a web browser after publishing in iSpring. Navigation buttons are added automatically 
iSpring as an authoring tool is not inexpensive; however, they do offer a fully functional free version without watermark, which only limits the number of assessment questions, types of questions, and number of slides. The use of iSpring is similar to other software packages, such as Adobe Presenter and Camtasia. The newest version of Adobe Presenter may be most comparable to iSpring (in case an institution has already licensing through Adobe).

\section{Creating Accessible Media}

Creating accessible media for all students is an important characteristic. Accessible course content is mandated through federal law (Americans with Disabilities Act, 1990; Section 504 of the Rehabilitation Act, 1973; Section 508 of Rehabilitation Act, 1973). The Web Content Accessibility Guidelines 2.0 (WCAG) were informed by Section 508 of the Rehabilitation Act of 1973 requirements, and they are often used by institutions as standards. There are three levels to WCAG, and the second level (i.e., Level $\mathrm{AA}$ ) is a typical level standard for institutions (McAlvage \& Rice, 2018).

Web accessibility is, of course, appropriate for individuals who are blind or deaf. However, individuals who have color blindness, low vision, progressive loss of vision, cognitive impairments, or some physical disabilities also benefit from web accessibility accommodations. Assistive technologies, such as screen readers and screen magnification, aid individuals with disabilities to navigate online courses and course materials (Singleton \& Neuber, 2020). Indeed, non-disabled students can also receive utility from changes made for improving web accessibility. Common strategies for making media accessible include (a) formatting text; (b) tagging images, charts, graphs, and maps; (c) formatting hyperlinks; (d) preparing PDFs; (e) formatting and tagging tables; and (f) adding transcripts and captioning for audio and video. Each of these is addressed in more detail.

\section{Formatting Text}

Text in general is very accessible to assistive technologies; however, additional formatting can be added to improve its navigation and usability. Faculty members can assign hierarchical headings in word processing documents and in web pages to improve their accessibility. Headings provide students using screen readers and students with low vision the ability to jump directly to specific content on a page (e.g., Singleton \& Neuber, 2020). Microsoft Word and Google Docs provide styles to build hierarchical structure into documents. The text formatting in styles can be edited for non-disabled students to adjust the visual formatting.

When formatting text, it is commonplace to use color and textual variations (e.g., bold, italics) to create contrast and indicate emphasis or importance. Screen readers do not read or interpret color, bold, italics, underline, or strikethrough; therefore, these formatting options should not be used as the singular method to express importance or communicate meaning (Blackboard, 2020). WCAG 2.0 also sets requirements for contrast between body text on a page and its background. WCAG 2.0 Level AA requires a minimum contrast ratio of 4.5:1 between a text color and its background color. Online tools like the WebAIM Color Contrast Checker (see Figure 7) can be used to test the contrast between colors. Increasing the contrast between text color and its background color also improves readability for adults with decreasing vision (McGinty, 2020;

Rummler et al., 2011).

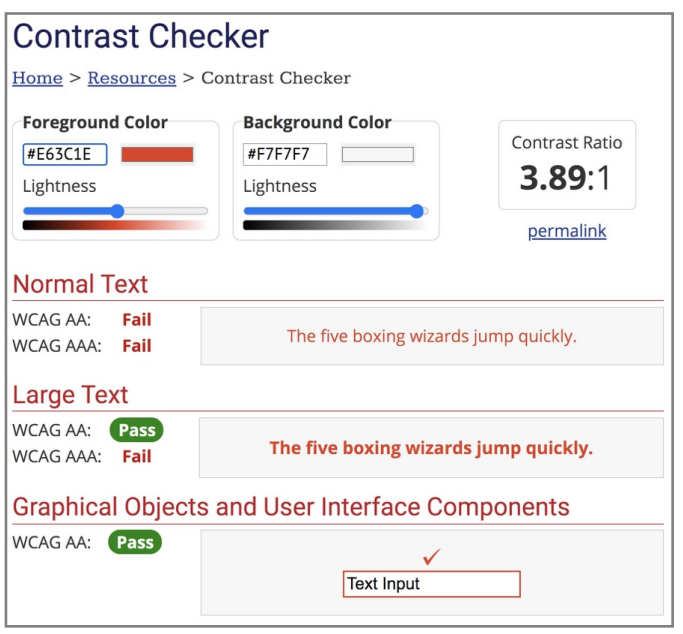

Figure 7. Color combinations from the red-templated web page from Figure 2 were analyzed with the WebAIM Color Contrast Checker. The resulting contrast was rated too low.

\section{Tagging Images, Charts, Graphs, and Maps}

Additional text descriptions can accompany charts, graphs, and maps. The descriptions can be (a) written by faculty members in the surrounding text; (b) added to a web page, CMS page, or word processing and digital slideshow's alternative text, or <alt>, tags; or (c) hyperlinked to another page for extended text descriptions (Coolidge et al., 2018). Adding <alt> tag descriptions is a routine strategy, and it is easy to accomplish. See, for example, Figure 8, where <alt $>$ tags can be added in a CMS, such as Blackboard Learn. The <alt $>$ tags can also be added in Microsoft Word and Microsoft PowerPoint, which aid screen readers (see Figure 9). Images can also be identified as "Decorative," which will embed appropriate tags/code for web pages and documents informing screen readers to skip these images.

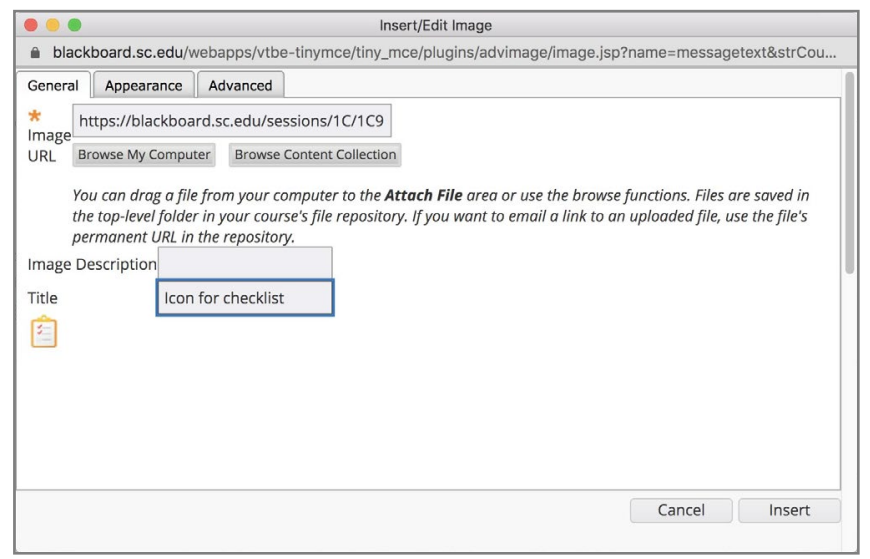

Figure 8. The 'Insert/Edit Image' dialog in Blackboard Learn allows for adding <alt> text in the Image Description field. 


\begin{tabular}{|c|}
\hline Accessibility \\
Inspection Results \\
$\nabla$ Errors \\
$\nabla$ Missing alternative text \\
Picture 3 \\
Picture 5 \\
Picture 6 \\
Picture 7 \\
Picture 8 \\
Picture 9 \\
\hline
\end{tabular}

\begin{tabular}{|l|}
\hline Accessibility \\
Inspection Results \\
$\nabla$ Errors \\
$>$ Missing alternative text (20) \\
$>$ Missing slide title (13) \\
$\nabla$ Warnings \\
$>$ Use captions for audio and video (1) \\
$>$ Hard-to-read text contrast (20) \\
$>$ Check reading order (13) \\
$\nabla$ Tips \\
$>$ Duplicate slide title (2) \\
$\nabla$ Intelligent Services \\
$>$ Suggested alternative text (12) \\
\end{tabular}

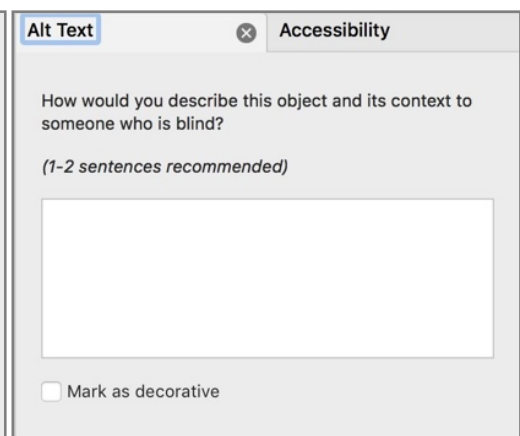

Figure 9. Accessibility checks can be conducted in Microsoft Word (left) and in Microsoft PowerPoint (center). Alternative (<alt>) text descriptions can be added in Microsoft Word and PowerPoint (right). Images can also be marked as decorative to inform screen readers to skip the image (right at bottom).

\section{Formatting Hyperlinks}

For screen readers to provide the most appropriate information to students with disabilities, hyperlinks should be descriptive, indicating where the link is directing the student. Instead of listing a long web link (i.e., URL) on a page or slide, provide text that indicates where a link is taking the student and hyperlink that text. On slides when providing links, it is best (a) to provide the hyperlinked descriptive text and (b) to provide in parentheses the URL without the hyperlink. Best practice to also include file type information as part of the link text to inform students what happen when they select the link:

\section{Download the APA 7th edition manuscript template [.docx]}

\section{Preparing PDFs}

Using PDFs can often be problematic for accessibility. Best practice is to provide the native (i.e., original) Microsoft Word or PowerPoint file along with a properly exported PDF. Using the Accessibility Checker in Microsoft Word and PowerPoint as described above and shown in Figure 9 aids in correctly formatting a PDF as well. Microsoft Word and PowerPoint allow faculty members to save/export to PDF and retain all tagging (i.e., <alt> tags, headings, pages). See Figure 10. However, at the time of this writing, Microsoft PowerPoint for MacOS does not match this functionality (see Figure 11). At this time, downloading Google Docs files does not create an accessible PDF (Portland Community College, 2020). Workarounds include using a Grackle Suite (see https://www. grackledocs.com/) add-on and downloading as Microsoft Office documents and using the "Save as ... PDF" function.

Scanned images or book pages converted to PDF should be avoided whenever possible. These PDFs are a series of images without text and raise substantial accessibility obstacles. These types of PDFs also prevent all students from conducting keyword searches within a document and using copy-paste features for notetaking (Blackboard Inc., 2020). If possible, use optical character recognition (OCR) converting the scans back into text. This works best with high quality scans, which are primarily text, with good contrast.

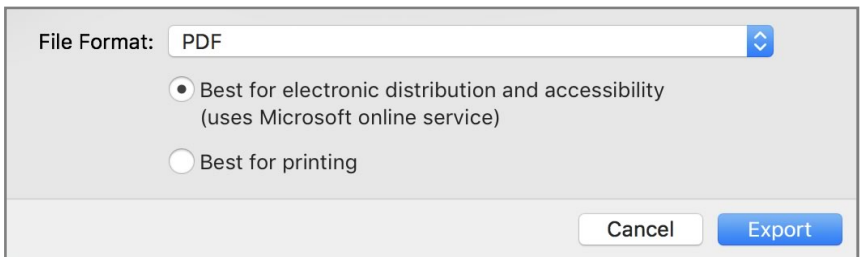

Figure 9. In Microsoft Word and PowerPoint, "Save as ... PDF" retains any document tagging. Select "Best for electronic distribution and accessibility," and there is no charge or storage to use Microsoft's online service. This functionality is not currently available in Microsoft PowerPoint for MacOS.

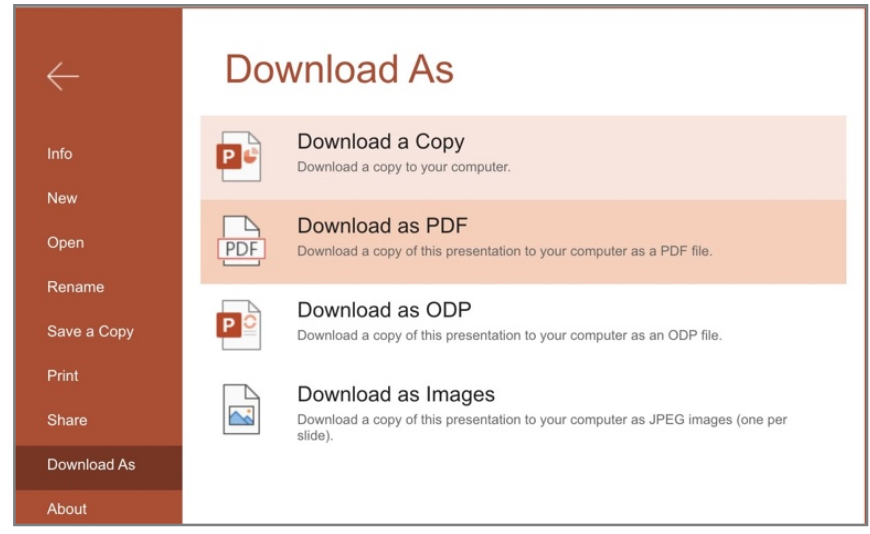

Figure 10. Microsoft PowerPoint for MacOS does not currently offer functionality for retaining any tagging when exporting as a PDF. A workaround is to open the slideshow in Microsoft 365 online and use "Download As...PDF" to retain the tagging.

\section{Formatting and Tagging Tables}

When using tables to display data, results, and categorize information, it is best to use the table functions within Microsoft Word and PowerPoint. Assistive technologies, like screen readers, can use the table header row to communicate cursor positioning to students. In particular, use row headings in tables and indicate the table has a header row (see Figure 12). 


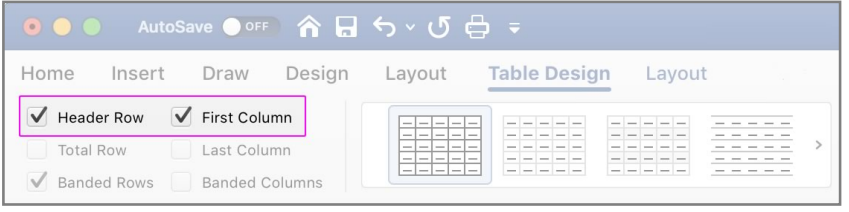

Figure 11. In Microsoft Word and PowerPoint, indicate a table has a first row with headings. After inserting a table and on the "Table Design" tab, select "Header Row" to add tagging for assistive technologies.

\section{Adding Transcripts and Captioning for Audio and Video}

For audio narrations or other audio recordings, such as podcasts, add a text transcript to accompany the audio. However, including the transcript text on-screen with the audio narration has been proven to be less effective for non-disabled students, violating Mayer's redundancy principle (Clark \& Mayer, 2016). So, it may be better to provide the transcript on a separate web page or as a download. When possible include textual descriptions of instructionally relevant non-speech, such as relevant music, background sounds, or intonations (Coolidge et al., 2018).

For video that includes synchronized audio narration, captioning should be used. Captions include a textual transcription of the spoken audio along with other audio sounds, such as laughter, applause, or music, and any other relevant information for understanding the video (Macy et al., 2018). When the language is set, YouTube will automatically generate a transcript (see Figure 13). The transcripts should be edited for accuracy and difficult disciplinary vocabulary or jargon.

Recently, Microsoft PowerPoint added captioning as subtitles when slideshows are presented live. Unfortunately, at this time, these captions are not stored and cannot be saved. To publish a Microsoft PowerPoint presentation with the subtitles, the presentation would need to be screen recorded as a video.

\section{CLOSING COMMENTS}

In this essay, I have described the theories, principles, pedagogies, and techniques I and other program faculty members at the University of South Carolina use to create asynchronous online courses and course materials for students in our concentration. My purpose was to make transparent how we translate theory and professional practices into everyday online teaching and learning. The practices I describe here have been developed and refined over many years and use professional practices from industry. However, many of these strategies can be adapted within other frameworks and with other readily available tools. As such, two reminders are essential for readers to scrutinize further before applying these practices into their own contexts.

First, the theories described throughout the paper heavily emphasize cognitivism. For example, information processing theory, dual coding theory, Mayer's cognitive theory of multimedia, cognitive load theory - all are referenced to support best practices for the development of online course materials. However, it should not be assumed that these theories alone represent the lens and framing for our teaching and learning. Indeed, they are not. Other constructivist pedagogies are also employed throughout our program as well. For example, during courses that emphasize academic writing, that is evaluating and synthesizing research, a cognitive apprenticeship approach (Collins et al., 1991) is used to teach the craft of writing syntheses. As described above, much of the constructionism and project-based learning used throughout our program also foster personal meaning construction. So, these strategies are not all predicated on a particular theoretical or pedagogical lens. Other topics, units, and courses use various pedagogy depending on the content and context. Therefore, I would be negligent to leave readers with the notion that the approaches presented here were the only pedagogy we use.

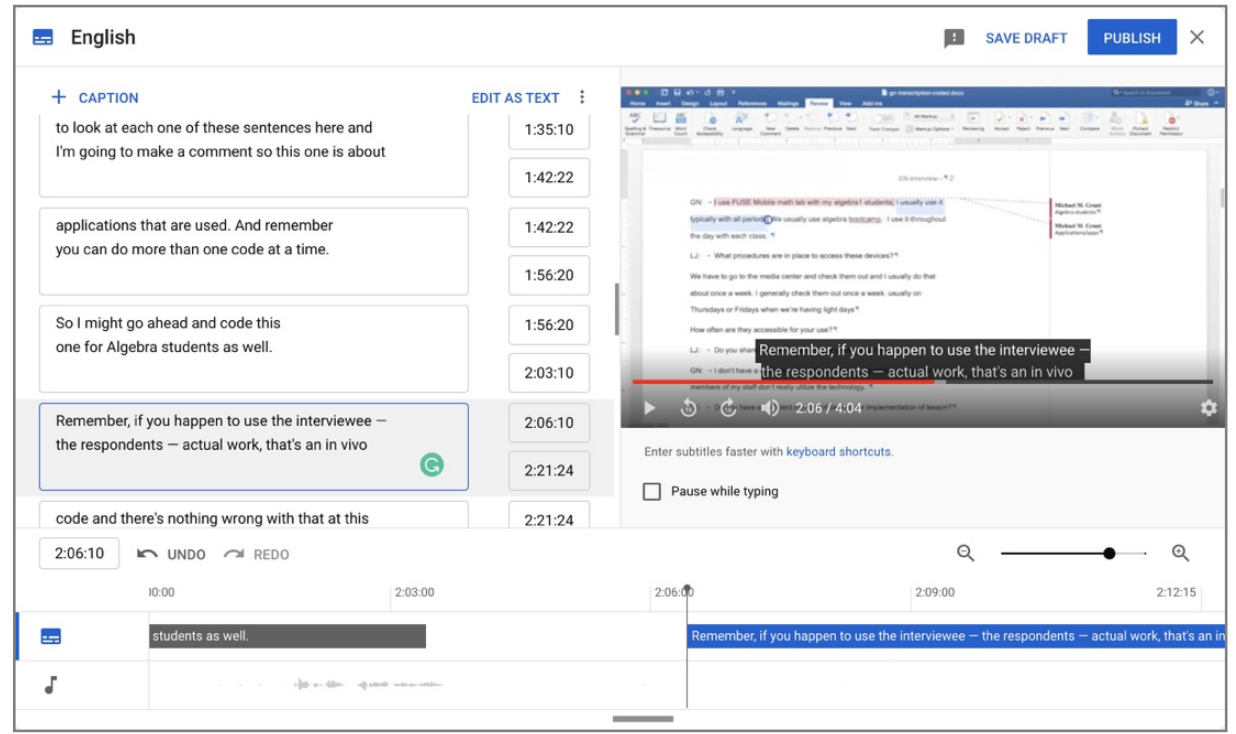

Figure 12. The captioning function in YouTube requires the language to be set. Then YouTube will automatically generate a transcript (left) and synchronize the text to the video (bottom). The captions can be edited directly in the text fields (left). The captioning then must be published (top right). 
Second, as stated early in this essay, these practices do not represent the only methods in which to do this work. There are many possible ways in which effective and successful asynchronous online courses and course materials can be designed and created. For example, John Curry, a colleague and critical friend at Idaho State University, has explained to me the design of some of his online course units/modules. He prefers to use a linear, step-by-step approach, where he asks students to accomplish certain activities in a specific order, inserting readings, tools, assignments, or discussions into a specific sequence. This means students may read articles and generate or respond to discussion prompts multiple times during a course unit's sequence of activities. I can see this would be particularly effective when wanting to document student's prior knowledge, new knowledge and application after a specific course reading, and subsequent reflections at the end of the unit/module in a KWL-chart approach. So, I encourage readers and other CPED-member faculty to use the strategies presented here to inspire their own work and contextual these approaches within their own pedagogical beliefs, online or blended courses, and programs, which are all unique.

\section{REFERENCES}

Alizadeh, M., Mehran, P., Koguchi, I., \& Takemura, H. (2019). Evaluating a blended course for Japanese learners of English: Why quality matters. International Journal of Educational Technology in Higher Education, 16(1), 1-21. https://doi.org/10.1186/s41239-019-0137-2

Alqurashi, E. (2019). Predicting student satisfaction and perceived learning within online learning environments. Distance Education, 40(1), 133-148. https://doi.org/10.1080/01587919.2018.1553562

Americans with Disabilities Act, Pub. L. No. 328 (1990).

Anderson, T. (2003). Modes of interaction in distance education: Recent developments and research questions. In M. G. Moore \& W. G. Anderson (Eds.), Handbook of distance education (pp. 129-169) Lawrence Erlbaum Associates.

Arslan-Ari, I., Ari, F., Grant, M. M., \& Morris, W. S. (2018). Action research experiences for scholarly practitioners in an online education doctorate program: Design, reality, and lessons learned. TechTrends, 62(5), 441 449. https://doi.org/10.1007/s11528-018-0308-3

Arslan-Ari, I., Ari, F., Grant, M. M., Vasconcelos, L., Tang, H., \& Morris, W. S. (2020). Becoming action researchers: Crafting the curriculum and learning experiences for scholarly practitioners in educational technology. In E. Romero-Hall (Ed.), Research methods in learning design and technology (pp. 78-93). Taylor \& Francis.

Baldwin, S. J., \& Ching, Y. (2019). Online course design: A review of the Canvas course evaluation checklist. International Review of Research in Open and Distributed Learning, 20(3). https://doi.org/10.19173/ irrodl. v20i3.4283

Baldwin, S. J., Ching, Y. H., \& Hsu, Y. C. (2018). Online course design in higher education: A review of national and statewide evaluation instruments. TechTrends, 62(1), 46-57. https://doi.org/10.1007/s11528 017-0215-z

Bates, A. W. (2019). Teaching in a digital age: Guidelines for designing teaching and learning (2nd ed.). Tony Bates Associates Ltd.

Blackboard Inc. (2020). Write accessible content. https://help.blackboard.com/ Accessibility/Write_Accessible_Content

Blackboard Inc. (2020). Accessibility best practices for transitioning to remote instruction. https://help.blackboard.com/Accessibility/Remote_ Instruction_Best_Practices

Bonfiglio, K., O'Bryan, A., Palavecino, P., \& Willibey, H. (2016). Increasing effectiveness on-line: Student-instructor interaction. National Social Science Proceedings: Denver Summer Seminar, 62(1), 1-16.

Clark, R. C., \& Lyons, C. (2011). Graphics for learning: Proven guidelines for planning, designing, and evaluating visuals in training materials (2nd ed.). Pfeiffer.
Clark, R. C., \& Mayer, R. E. (2016). E-learning and the science of instruction: Proven guidelines for consumers and designers of multimedia learning (4th ed.). Wiley.

Collins, A., Brown, J. S., \& Holum, A. (1991). Cognitive apprenticeship: Making thinking visible. American Educator, 15(3), 6-11, 38-46.

Collins, D., Weber, J., \& Zambrano, R. (2014). Teaching business ethics online: Perspectives on course design, delivery, student engagement, and assessment. Journal of Business Ethics, 125, 513-529. https://doi.org/ 10.1007/s10551-013-1932-7

Coolidge, A., Doner, S., Robertson, T., \& Gray, J. (2018). Accessibility toolkit (2nd ed., Vol. 2). BCcampus.

Crews, T., \& Butterfield, J. B. (2014). Data for flipped classroom design: Using student feedback to identify the best components from online and faceto-face classes. Higher Education Studies, 4(3), 38-47. https://doi.org/ $10.5539 /$ hes.v4n3p38

Day, S., \& Erturk, E. (2017). E-Learning objects in the cloud: SCORM compliance, creation and deployment options. Knowledge Management and E-Learning, 9(4), 449-467. https://doi.org/10.34105/j.kmel.2017.09. 028

DiPietro, M., Ferdig, R. E., Black, E. W., \& Preston, M. (2008). Best practices in teaching $\mathrm{K}-12$ online: Lessons learned from Michigan Virtual School teachers. Journal of Interactive Online Learning, 7(1), 10-35.

Dron, J., \& Anderson, T. (2014). Teaching crowds. Athabasca University Press. https://doi.org/10.15215/aupress/9781927356807.01

Edutechnica. (2020). LMS data - Spring 2020 updates. https://edutechnica com/2020/02/02/lms-data-spring-2020-updates/

Emory, B. (2019). Cognitive load theory and instructional message design. In M. Ramlatchan (Ed.), Instructional message design: Theory, research, and practice (pp. 1-28). Kindle Direct Publishing.

Ertmer, P. A., \& Newby, T. J. (1993). Behaviorism, cognitivism, constructivism Comparing critical features from an instructional design perspective. Performance Improvement Quarterly, 6(4), 50-72. https://doi.org/10. 1111/j.1937- 8327.1993.tb00605.x

Ertmer, P. A., \& Ottenbreit-Leftwich, A. T. (2010). Teacher technology change: How knowledge, confidence, beliefs, and culture intersect. Journal of Research on Technology in Education, 42(3), 255-285.

Fleming, M. L., \& Levie, W. H. (1993). Instructional message design: Principles from the behavioral and cognitive sciences (2nd ed.). Educational Technology Publications

Garrison, R., Anderson, T., \& Archer, W. (2000). Critical inquiry in a text-based environment: Computer conferencing in higher education. The Internet and Higher Education, 2(2-3), 87-105.

Gilliham, J. C., \& Williams, N. V. (2020). Taking it to the next level: Improving online courses with research-based best practices [Conference presentation]. Carnegie Project on the Education Doctorate annual convening

Glazier, R. A. (2016). Building rapport to improve retention and success in online classes. Journal of Political Science Education, 12(4), 437-456. https://doi.org/10.1080/15512169.2016.1155994

Gonzalez-Barbone, V., \& Anido-Rifon, L. (2008). Creating the first SCORM object. Computers and Education, 51(4), 1634-1647. https://doi.org/10. 1016/j.compedu.2008.04.004

Grant, M. M. (2018). Recognizing our accomplishments, saying thank you, and looking ahead for IJPBL and the field. Interdisciplinary Journal of Problem-Based Learning, 12(2). https://doi.org/10.7771/1541-5015.1831

Havice, P. A., Foxx, K. W., Davis, T. T., \& Havice, W. L. (2010). The impact of rich media presentations on a distributed learning environment: Engagement and satisfaction of undergraduate students. Quarterly Review of Distance Education, 11(1), 53-58.

Hill, J. R., \& Hannafin, M. J. (2001). Teaching and learning in digital environments: The resurgence of resource-based learning. Educational Technology Research and Development, 49(3), 37-52.

Hodges, C. B., Moore, S., Lockee, B., Trust, T., \& Bond, M. A. (2020). The difference between emergency remote teaching and online learning. EDUCASE Review.

Johansson-sköldberg, U., \& Woodilla, J. (2013). Design thinking: Past, presen and possible futures. Creativity and Innovation Managament, 22(2), 121 146. https://doi.org/10.1111/caim.12023

Kafai, Y. B., \& Resnick, M. (1996). Constructionism in practice: Designing, thnking, and learning in a digital world. Lawrence Erlbaum Associates. 
Kearns, L. R., \& Mancilla, R. (2017). The impact of Quality Matters professional development on teaching across delivery formats. American Journal of Distance Education, 31(3), 185-197. https://doi.org/10.1080/ 08923647.2017 .1301145

Kirschner, P. A., Sweller, J., \& Clark, R. E. (2006). Why minimal guidance during instruction does not work. Educational Psychologist, 41(2), 87-98. https://doi.org/10.1207/s15326985ep4102

Knowles, M. S. (1975). Self-directed learning. Association Press.

Krajcik, J. S., \& Blumenfeld, P. C. (2006). Project-based learning. In R. K. Sawyer (Ed.), Cambridge handbook of the learning sciences (pp. 317405). Cambridge University Press.

Macy, M., Macy, R., \& Shaw, M. E. (2018). Bringing the ivory tower into students' homes: Promoting accessibility in online courses. Ubiquitous Learning, 11(1), 13-21. https://doi.org/10.18848/1835-9795/CGP/v11i01/ 13-21

Martin, F., Budhrani, K., Kumar, S., \& Ritzhaupt, A. (2019). Award-winning faculty online teaching practices: Roles and competencies. Online Learning Journal, 23(1), 184-205. https://doi.org/10.24059/olj.v23i1.1329

Martin, F., Ritzhaupt, A., Kumar, S., \& Budhrani, K. (2019). Award-winning faculty online teaching practices: Course design, assessment and evaluation, and facilitation. Internet and Higher Education, 42(November 2018), 34-43. https://doi.org/10.1016/j.iheduc.2019.04.001

Mayer, R. E. (2008). Applying the science of learning: Evidence-based principles for the design of multimedia instruction. American Psychologist, 63(8), 760-769. https://doi.org/10.1037/0003066X.63.8.760

McAlvage, K., \& Rice, M. (2018). Access and accessibility in online learning: Issues in higher education and K-12 contexts. Online Learning Consortium Research Center for Digital Learning and Leadership. https://files.eric.ed.gov/fulltext/ED593920.pdf

McGee, P., \& Reis, A. (2012). Blended course design: A synthesis of best practices. Journal of Asynchronous Learning Networks, 16(4), 7-22.

McGhan, S. J., Jackson, C. M., \& Premer, K. (2015). Online course quality assurance: Development of a quality checklist. InSight; $A$ Journal of Scholarly Teaching, 10(1), 126-140.

McGinty, J. M. (2020). Accessible digital learning materials for inclusive adult education. Adult Learning, Online First, 1045159520961470. https://doi. org/10.1177/1045159520961470

Morrison, G. R., Ross, S. M., Kalman, H. K., \& Kemp, J. E. (2013). Designing effective instruction (7th ed.). Wiley.

Paivio, A. (1991). Dual coding theory: Retrospect and current status. Canadian Journal of Psychology/Revue Canadienne de Psychologie, 45(3), 255287. https://doi.org/10.1037/h0084295

Papert, S. (1991). Situating constructionism. In I. Harel \& S. Papert (Eds.), Constructionism. Ablex Publishing Corporation.

Portland Community College. (2020). PDF document accessibility. https://www. pcc.edu/instructional-support/accessibility/pdf/\#tabexporting-google-files

Ramlatchan, M. (2019). Multimedia learning theory and instructional message design. In M. Ramlatchan (Ed.), Instructional message design: Theory, research, and practice (pp. 1-29). Kindle Direct Publishing.

Reed, S. K. (2006). Cognitive architectures for multimedia learning Educational Psychologist, 41(2), 87-98.

Rummler, K., Seipold, J., Pachler, N., \& Attwell, G. (2011). Supporting learning on building sites with mobile technologies. In K. Rummler, J. Seipold, E. Lübcke, N. Pachler, \& G. Attwell (Eds.), Mobile learning: Crossing boundaries in convergent environments (pp. 157-160). London Mobile Learning Group.

Sadaf, A., Martin, F., \& Ahlgrim-Delzell, L. (2019). Student perceptions of the impact of quality matters-certified online courses on their learning and engagement. Online Learning Journal, 23(4), 214-233. https://doi.org/ 10.24059/olj.v23i4.2009

Saunders-Stewart, K. S., Gyles, P. D. T., \& Shore, B. M. (2012). Student outcomes in inquiry instruction: A literature-derived inventory. Journal of Advanced Academics, 23(1), 5-31. https://doi.org/10.1177/ $1932202 X 11429860$

Section 504 of the Rehabilitation Act, Pub. L. No. 394 (1973).

Section 508 of Rehabilitation Act, Pub. L. No. 794d (1973).

Singleton, K. J., \& Neuber, K. S. (2020). Examining how students with visual impairments navigate accessible documents. Journal of Visual
Impairment and Blindness, 114(5), 393-405. https://doi.org/10.1177/ 0145482X20953268

Smith, K. M., \& Boling, E. (2009). What do we make of design? Design as a concept in educational technology. Educational Technology, 49(4), 3-17.

Strecker, S., Baumöl, U., Karagiannis, D., Koschmider, A., Snoeck, M., \& Zarnekow, R. (2019). Five inspiring course (re-)designs: Innovating teaching and learning in higher education. Business Information Systems Engineering, 61, 241-252. https://doi.org/https://doi.org/10.1007/s12599019-00584-5

Sweller, J., van Merriënboer, J. J. G., \& Paas, F. (1998). Cognitive architecture and instructional design. Educational Psychology Review, 10(3), 251296. https://doi.org/10.1007/s10648-019-09465-5

Tuovinen, J. E. (2000). Multimedia distance education interactions Educational Media International, 37(1), 16-24. https://doi.org/10.1080/ 095239800361473

Wiggins, G., \& McTighe, J. (2005). Understanding by design (2nd ed.). Association for Supervision and Curriculum Development.

Zawacki-Richter, O. (2017). Distance education. In M. Peters (Ed.), Encyclopedia of educational philosophy and theory. Springer Science + Business Media.

\section{APPENDIX A: LIST OF TOOLS AND RESOURCES}

\section{Course Planning}

- City University of New York course planning template: https://spscoursedesign.commons.gc.cuny.edu/planning-out-yourcourse/

- Course Mapping Guide: https://www.coursemapguide.com/

\section{Developing Rich Media}

- Embedding YouTube videos into web pages: https://support.google.com/youtube/answer/171780?hl=en

- Embedding Slideshare into web pages: https://www.linkedin.com/help/slideshare/answer/53686

- Screen recording with Screencast-o-matic: https://screencast-o-matic.com/

- Screen recording with Screencastify: https://www.screencastify.com/

- Screen recording in Zoom: https://support.zoom.us/hc/en-us/articles/201362473-Localrecording

- Recording audio narration in Microsoft PowerPoint: https://support.microsoft.com/en-us/office/record-a-slide-showwith-narration-and-slide-timings-0b9502c6-5f6c-40ae-b1e7e47d8741161c

- Recording audio narration in Apple Keynote: https://support.apple.com/guide/keynote/record-audio$\tan 8 \mathrm{a} 5 \mathrm{df9}$ cc5/mac

- Exporting a Microsoft PowerPoint slideshow with audio narration as a video (Windows):

https://support.microsoft.com/en-us/office/turn-your-presentationinto-a-video-c140551f-cb37-4818-b5d4-3e30815c3e83

- Exporting a Microsoft PowerPoint slideshow with audio narration as a video (Mac):

https://support.microsoft.com/en-us/office/export-your-powerpointfor-mac-presentation-as-a-different-file-format-0547523c-56c44799-b5f7-6257907c09ee 
- iSpring Suite: https://www.ispringsolutions.com/

- iSpring Free version: https://www.ispringsolutions.com/ispring-free

- Adobe Presenter: https://www.adobe.com/products/presenter.html

\section{Creating Accessible Documents}

- Indiana University site for creating accessible Microsoft Office documents:

https://kb.iu.edu/d/auim

- WebAIM Color Contrast Checker: https://webaim.org/resources/contrastchecker/

- WebAIM Link Contrast Checker: https://webaim.org/resources/linkcontrastchecker/

- Colour Contrast Analyzer free software for MacOS and Windows:

https://developer.paciellogroup.com/resources/contrastanalyser/

- $\quad$ Color.review website contrast checker: https://color.review/

- $\quad$ See Coolidge et al. (2018) for an accessibility checklist

- $\quad$ Adding <alt> tags to Microsoft Word and Powerpoint: https://support.microsoft.com/en-us/office/add-alternative-textto-a-shape-picture-chart-smartart-graphic-or-other-object44989b2a-903c-4d9a-b742-6a75b451c669

- Create accessible PDFs in Microsoft Word and Powerpoint: https://support.microsoft.com/en-us/office/create-accessiblepdfs-064625e0-56ea-4e16-ad71-3aa33bb4b7ed

- WebAIM Word and PowerPoint Accessibility Checklist: https://webaim.org/resources/evaloffice/

- $\quad$ Saving/exporting Microsoft Word and PowerPoint documents to PDF and preserve tagging: https://support.microsoft.com/en-us/office/create-accessiblepdfs-064625e0-56ea-4e16-ad71-3aa33bb4b7ed

- Create accessible PDFs from Google Docs: https://www.pcc.edu/instructional-support/accessibility/pdf/\#tabexporting-google-files

- Using OCR in Adobe Acrobat Pro: https://helpx.adobe.com/acrobat/using/edit-scanned-pdfs.html

- $\quad$ Using OCR in Google Docs: https://support.google.com/drive/answer/176692

- $\quad$ Using OCR in Microsoft OneNote: https://support.microsoft.com/en-us/office/copy-text-frompictures-and-file-printouts-using-ocr-in-onenote-93a70a2f-ebcd42dc-9f0b-19b09fd775b4

- Opening a PDF in Microsoft Word: https://support.microsoft.com/en-us/office/edit-a-pdf-b2d1d7296b79-499a-bcdb-233379c2f63a

- $\quad$ Free OCR software: https://www.easepdf.com/topics/top-free-ocr-software.html

- Using automatic captioning in YouTube: https://support.google.com/youtube/answer/6373554
- Using subtitles in Microsoft PowerPoint: https://support.microsoft.com/en-us/office/present-with-realtime-automatic-captions-or-subtitles-in-powerpoint-68d20e49aec3-456a-939d-34a79e8ddd5f 